\title{
Investigating changes in lake systems in the south-central Tibetan Plateau with multi-source remote sensing
}

\author{
WU Yanhong ${ }^{1}$, ZHANG Xin ${ }^{2}$, ZHENG Hongxing ${ }^{3}$, 'LI Junsheng ${ }^{1}$, \\ WANG Zhiying ${ }^{1,4}$ \\ 1. Key Laboratory of Digital Earth Science, Institute of Remote Sensing and Digital Earth, CAS, Beijing 100101, \\ China; \\ 2. College of Global Change and Earth System Sciences, Beijing Normal University, Beijing 100875, China; \\ 3. CSIRO Land and Water, Canberra, Australian Capital Territory, Australia; \\ 4. College of Geography and Environment, Shandong Normal University, Jinan 250014, China
}

\begin{abstract}
Lakes in the Tibetan Plateau are considered sensitive responders to global warming. Variations in physical features of lake systems such as surface area and water level are very helpful in understanding regional responses to global warming in recent decades. In this study, multi-source remote sensing data were used to retrieve the surface area and water level time series of five inland lakes in the south-central part of the Tibetan Plateau over the past decades. Changes in water level and surface area of the lakes were investigated. The results showed that the water level of three lakes (Puma Yumco, Taro Co, Zhari Namco) increased, with expanding surface area, while the water levels of the other two lakes (Paiku Co, Mapam Yumco) fell, with shrinking area. The water levels of the lakes experienced remarkable changes in 2000-2012 as compared with 1976-1999. Spatially, lakes located at the southern fringe of the Tibetan Plateau showed consistency in water level changes, which was different from lakes in the central Tibetan Plateau.
\end{abstract}

Keywords: water level; surface area; lake system; remote sensing; Tibetan Plateau

\section{Introduction}

The Tibetan Plateau is known as the "Third Pole of the Earth" (Qiu, 2008), with an area of approximately $250,000 \mathrm{~km}^{2}$ and an average elevation of above $4000 \mathrm{~m}$. The plateau is also considered as the Asia Water Tower (Lu et al., 2005), where the total lake area accounts for approximately $51.4 \%$ of that of all lakes in China (Yao and Zhu, 2006). It is believed that changes in the surface area and water level of lakes in the plateau are closely linked to cli-

Received: 2015-12-30 Accepted: 2016-07-15

Foundation: The "Strategic Priority Research Program (B)" of the Chinese Academy of Sciences, No.XDB03030406; National Natural Science Foundation of China, No.41371218, No.41165011

Author: Wu Yanhong (1979-), Associate Professor, specialized in global change and remote sensing application. E-mail:wuyh@radi.ac.cn

"Corresponding author: Li Junsheng (1979-), Associate Professor, E-mail: 1ijs@radi.ac.cn 
mate change and the accompanying glacier retreat (Zhu et al., 2010), which in turn have shown adverse impacts on the regional ecosystem and environment (Solomon et al., 2007). Several studies have been conducted to investigate changes in the lake system of the plateau (e.g., Ye et al., 2007; Wu and Zhu, 2008; Liu et al., 2009; Meng et al., 2012; Lei et al., 2013), as well as to identify the main drivers of the changes (Yang et al., 2011; Zhang et al., 2011a). However, in the vast area of the Tibetan Plateau, ground observations of lake properties are rarely available, which makes it a challenge to detect long-term changes in the lake systems as a consequence of global climate change.

Remote sensing (RS) has been widely accepted as an important technique in earth observation for its outstanding capacity for large-scale dynamic tracking. The remotely sensed data is extremely valuable for data-sparse regions like the Tibetan Plateau by providing information never observed on the ground. Some RS products have enabled researchers to extract essential and valuable information on lake properties such as surface area, water level and water temperature. With the rapid development of RS, more RS data at different resolutions and covering different periods are becoming available. Data from a specific single RS source may offer advantages such as high consistency, but may suffer from limitations of temporo-spatial resolution or observation period covered. For instance, the ICESat (Ice, Cloud and Land Elevation Satellite) is considered to be particularly meaningful in detecting dynamic changes of inland lake levels, owing to its relatively high precision and accuracy (Zhang et al., 2011b, 2013). However, it is not applicable for reflecting long-term changes of the lake system or for assessing the impact of climate change, owing to its limited observation period (2003-2009). To take advantage of the enriching RS data, a multi-source RS technique has been developed to enhance the capacity of observation (Markham and Helder, 2012). In general, multi-source RS can provide more useful observations than single source RS, by combining and integrating the available information from different RS platforms.

This study aimed to investigate the long-term changes in surface area and water level for lake systems in the Tibetan Plateau by integrating images from different RS data sources. First, the relationships between the remotely sensed data were characterized; then, on this basis, a time series of surface area and water level was developed for the period 1972-2012. The long-term changes of the lake system were then investigated, and the potential impacts of climate change are discussed.

\section{Study area and data}

\subsection{Selected lakes}

Five lakes (Table 1) in the southern Lake District of the Tibetan Plateau were selected for investigation in this study. The district is located to the west of $94^{\circ} \mathrm{E}$ and south of $32^{\circ} \mathrm{N}$ (Figure 1). The Zhari Namco (ZNC) and Taro Co (TRC) lakes at the south of the Tibetan Plateau belong to the semi-arid zone of Qiangtang alpine grassland, where precipitation and glacier/snow melt flow are the main water sources of the lake systems. Then Mapam Yumco (MYC), Paiku Co (PKC), and Puma Yumco (PYC) lakes are all located along the fringe of the southern part of the Tibetan Plateau. PKC and PMC are recharged by precipitation and melting glacier flow, whereas MYC is supplied by precipitation and stream flow. 
Table 1 Geographical characteristics of the selected lakes

\begin{tabular}{cccccc}
\hline Lakes & Location & Area $\left(\mathrm{km}^{2}\right)$ & Temperature $\left({ }^{\circ} \mathrm{C}\right)$ & Precipitation $(\mathrm{mm})$ & Glacier meltwater supply \\
\hline Puma Yumco & $28^{\circ} 30^{\prime}-28^{\circ} 38^{\prime} \mathrm{N}$ & 287.55 & -1.13 & 287 & Yes \\
& $90^{\circ} 13^{\prime}-90^{\circ} 33^{\prime} \mathrm{E}$ & & & & No \\
Zhari Namco & $30^{\circ} 44^{\prime}-31^{\circ} 05^{\prime} \mathrm{N}$ & 971.88 & -1.04 & 174 & No \\
& $85^{\circ} 20^{\prime}-85^{\circ} 54^{\prime} \mathrm{E}$ & & & 154 & Yes \\
Mapam Yumco & $30^{\circ} 34^{\prime}-30^{\circ} 47^{\prime} \mathrm{N}$ & 409.09 & 5.60 & & 654 \\
& $81^{\circ} 22^{\prime}-81^{\circ} 27^{\prime} \mathrm{E}$ & & & \\
Paiku Co & $28^{\circ} 46^{\prime}-29^{\circ} 02^{\prime} \mathrm{N}$ & 272.35 & -1.20 & & No \\
& $85^{\circ} 30^{\prime}-85^{\circ} 42^{\prime} \mathrm{E}$ & & & & \\
Taro Co & $31^{\circ} 03^{\prime}-31^{\circ} 13^{\prime} \mathrm{N}$ & 483.45 & -0.74 & & \\
\hline
\end{tabular}

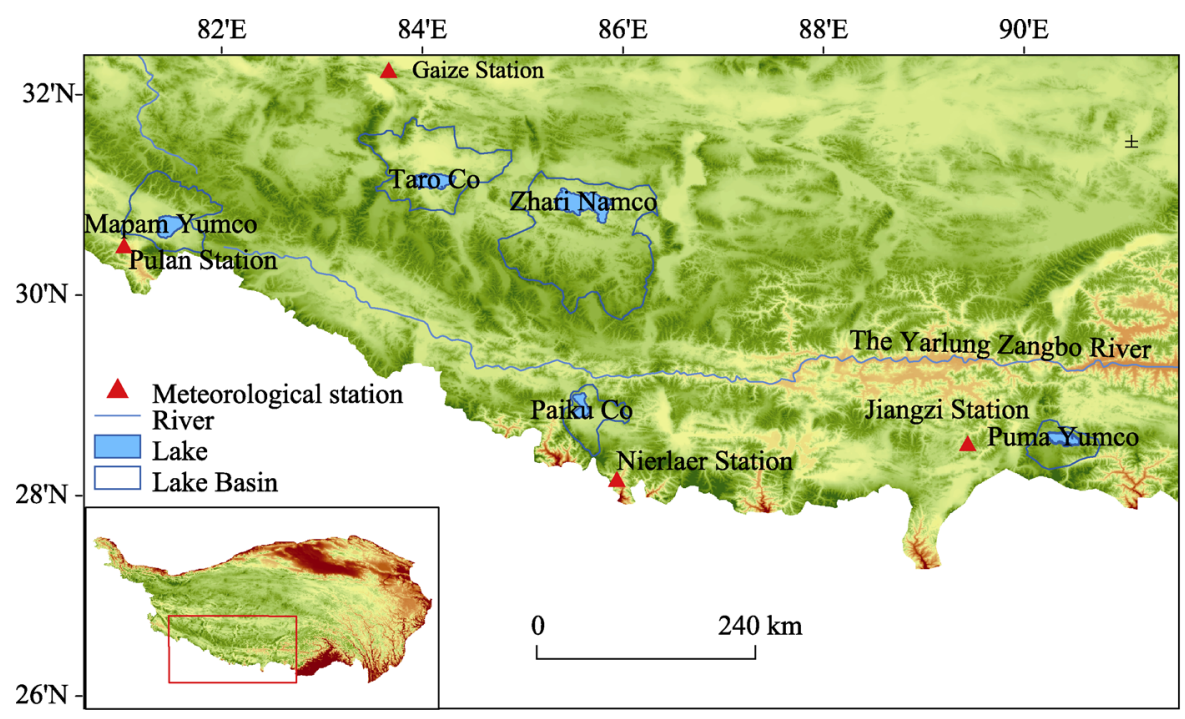

Figure 1 Locations of the five selected lakes in the Tibetan Plateau

\subsection{Data}

The multi-source RS data used in this study included Landsat MSS/TM/ETM, MODIS (Moderate-Resolution Imaging Spectroradiometer) surface reflectance outputs, and ICESat GLAS (Geoscience Laser Altimeter System) laser altimeter data (Table 2), among which the Landsat satellite series provides the longest continuous record of observations. The spatial resolution of the MSS (Multispectral Scanner) sensor is approximately $79 \mathrm{~m}$, with four bands ranging from the visible blue to the near-infrared (NIR) wavelengths. The TM sensor has a spatial resolution of $30 \mathrm{~m}$ for the six reflective bands and $120 \mathrm{~m}$ for the thermal band (Chander et al., 2009). The MODIS instrument is carried by two polar orbiting satellites (Terra and Aqua). The system is able to acquire data of the entire earth's surface every 1 to 2 days in 36 spectral bands from the Terra satellite in the morning and the Aqua satellite in the afternoon (Kropáčk et al., 2013). The ICESat was the first laser altimeter satellite, launched in 2003, equipped with a GLAS (laser altimeter) that had a vertical ground resolution of up to $10 \mathrm{~cm}$ and a horizontal resolution of $170 \mathrm{~m}$ (Zhang et al., 2011c). 
Table 2 Multi-source remotely sensed data used for extraction of lake area and level

\begin{tabular}{|c|c|c|c|}
\hline \multirow{2}{*}{ Lake } & \multicolumn{2}{|c|}{ Surface area } & \multirow{2}{*}{ Water level ICESat } \\
\hline & Landsat & MODIS & \\
\hline Puma Yumco (PYC) & 1972-2011 (35 images) & 2001-2012 (552 images) & 2003-2009 (14 periods) \\
\hline Zhari Namco (ZNC) & 1976-2012 (48 images) & 2001-2012 (552 images) & 2003-2009 (19 periods) \\
\hline Mapam Yumco (MYC) & 1972-2012 (39 images) & 2001-2012 (552 images) & 2003-2009 (19 periods) \\
\hline Paiku Co (PKC) & 1976-2012 (27 images) & 2001-2012 (552 images) & 2003-2009 (18 periods) \\
\hline Taro Co (TRC) & 1976-2012 (40 images) & 2001-2012 (552 images) & 2003-2009 (12 periods) \\
\hline
\end{tabular}

In this study, Landsat MSS images (14 scenes) were used to extract the water level before 1980, while TM/ETM+ images were used for the period since 1980 (92 scenes in TM and 117 scenes in ETM). The Landsat images were selected from the same months, mainly between November and March, to eliminate seasonal influences on water level. MOD09A1 surface reflectance products for the period 2001-2012 were selected for use, which were 8 -day synthetic images with a spatial resolution of $500 \mathrm{~m}$. There were 46 scenes for each year, and 552 scenes in total were used here. Water levels of all five lakes could be obtained from the GLA14 product over the period from February 2003 to October 2009, where observations on 82 specific days were available.

\section{Methods}

\subsection{Estimating lake surface area}

To estimate the surface area of the lakes, an automated threshold method was adopted to segment the land and water pixels (Li et al., 2011) in Landsat and MODIS satellite images. The most commonly used indices for water object identification include the Normalized Difference Water Index (NDWI) (McFeeters, 1996), the Modified Normalized Difference Water Index (MNDWI) (Xu, 2005), the Enhanced Water Index (EWI) (Yan et al., 2007), and the Normalized Water Index (NWI) (Ding, 2009). In this study, the NDWI was used, which is capable of effectively strengthening water-related information while simultaneously weakening information pertaining to land, mountain, and soil. The NDWI was calculated as:

$$
N D W I=\frac{\rho_{\text {GREEN }}-\rho_{\text {NIR }}}{\rho_{\text {GREEN }}+\rho_{\text {NIR }}}
$$

where $\rho_{\text {GREEN }}$ and $\rho_{\text {NIR }}$ are green band and near-infrared band, respectively, which correspond to bands 2 and 4 in the Landsat TM/ETM+ sensor, to bands 4 and 7 in Landsat MSS, and to bands 4 and 2 in MODIS.

The "Global-local" segmentation scheme used herein was based on the distribution mode of the NDWI histogram, in which areas of mixed water and land are of bimodal distribution whereas the non-water-object area is of unimodal distribution (Li et al., 2011). A minimum threshold value was first used as the initial value to roughly identify the boundary of the water object. For each water object, a more precise boundary was further delineated according to the threshold value calculated by Equation 2:

$$
T=\frac{\mu_{\text {water }} \times \sigma_{\text {land }}+\mu_{\text {land }} \times \sigma_{\text {water }}}{\mu_{\text {water }}+\mu_{\text {land }}}
$$


where $T$ represents the threshold value; $\mu_{\text {water }}$ and $\mu_{\text {land }}$ are the average values of the water body and land pixels, respectively; while $\sigma_{\text {water }}$ and $\sigma_{\text {land }}$ are the corresponding variance. The detailed process is shown in Figure 2. The boundaries of the lakes in the Tibetan Plateau were then extracted automatically using scripts in the IDL (Interface Description Language) platform.

\subsection{Extending water level observations}

As mentioned, the water level data from ICESat is of high quality but only available for the period 2003-2009. To investigate the changes in the lake system over a longer period (1972-2012), a method was developed to extend the water level series based on the relationships between the available data from different RS platforms. Among the three RS data sources, Landsat has the longest observation records, which can be traced back to 1972, providing the possibility to extend the water level sequence. However, there are relatively few concurrent observations between Landsat and which makes it difficult if not impossible to derive directly the relationship between Landsat and ICESat. Fortunately, lake surface area data are available in MODIS for the period 2001-2012, which includes simultaneous observations with both Landsat and ICESat but for different periods. Therefore, the MODIS data can be used as a bridge to link together Landsat and ICESat data. Taking into consideration the availability of data from the three RS platforms, we could then extend the lake level sequence according to the following expression:

$$
\left\{\begin{array}{l}
\mathrm{L}_{1}^{\prime}=f\left(A_{\text {MODIS }}\right) \\
\mathrm{L}_{2}^{\prime}=f\left[g\left(A_{\text {Landsat }}\right)\right]
\end{array}\right.
$$

where $A_{\text {MODIS }}$ and $A_{\text {Landsat }}$ are the lake area observed by MODIS and Landsat, respectively. $\mathrm{L}_{1}^{\prime}$ and $\mathrm{L}_{2}^{\prime}$ are the estimated lake level using MODIS and Landsat observations, respectively. As shown in expression (3), firstly, the relationship function $f(x)$ between water level from ICESat and surface area from MODIS was established for the period 2003-2009. As a close relationship was maintained between them, the water level could then be estimated according to lake surface area from MODIS. To extend the water level sequence to a longer period, the function $g(x)$ representing the relationship between the surface area data of MODIS and Landsat was derived given observations from MODIS and Landsat for the period 2001-2012. 


\section{Results and discussion}

\subsection{Relationships between multi-source remotely sensed data}

As shown in Table 3, regression models were built for each lake considering the relationship between water level from ICESat and surface area from MODIS. Meanwhile, the relationships between surface area data from MODIS and Landsat are shown in Table 4. It was found that all the regression models were statistically significant, with rather high coefficients of determination $\left(R^{2}\right)$. The results indicated that the methods described above were applicable to extend the time series of lake level data, although some bias may exist.

Table 3 Regressive functions between ICESat water level and MODIS surface area data

\begin{tabular}{lccc}
\hline \multicolumn{1}{c}{ Name of lake } & \multicolumn{1}{c}{ Regression equation $^{\mathrm{a}}$} & $R^{2}$ & Significance level $^{\circ}$ \\
\hline Puma Yumco (PYC) & $\mathrm{Y}=\ln (x)^{*} 661.509-3468.351$ & 0.721 & $\alpha=0.05$ \\
Mapam Yumco (MYC) & $\mathrm{Y}=\ln (x)^{*} 242,184-1051.499$ & 0.765 & $\alpha=0.05$ \\
Taro Co (TRC) & $\mathrm{Y}=\ln (x)^{*} 1429.233-8369.144$ & 0.762 & $\alpha=0.01$ \\
Paiku Co (PKC) & $\mathrm{Y}=\ln (x)^{*} 411.402-2035.593$ & 0.670 & $\alpha=0.05$ \\
Zhari Namco (ZNC) & $\mathrm{Y}=\ln (x)^{*} 678.377-3682.608$ & 0.492 & $\alpha=0.05$ \\
\hline
\end{tabular}

${ }^{\mathrm{a}}$ Note: $x$ denotes the surface area obtained from MODIS data, and Y denotes the water level obtained from ICESat data.

Table 4 Regressive functions between MODIS and Landsat surface areas

\begin{tabular}{lccc}
\hline \multicolumn{1}{c}{ Name of lake } & Regression equation ${ }^{\mathrm{a}}$ & $R^{2}$ & Significance level $^{\circ}$ \\
\hline Puma Yumco (PYC) & $\mathrm{Y}=\ln (x)^{*} 16.289-4918.349$ & 0.433 & $\alpha=0.05$ \\
Mapam Yumco (MYC) & $\mathrm{Y}=\ln (x)^{*} 19.660-4468.897$ & 0.632 & $\alpha=0.01$ \\
Taro Co (TRC) & $\mathrm{Y}=\ln (x)^{*} 30.442-4380.375$ & 0.575 & $\alpha=0.01$ \\
Paiku Co (PKC) & $\mathrm{Y}=\ln (x)^{*} 32.735-4396.264$ & 0.481 & $\alpha=0.01$ \\
Zhari Namco (ZNC) & $\mathrm{Y}=\ln (x)^{*} 15.181-4508.691$ & 0.656 & $\alpha=0.01$ \\
\hline
\end{tabular}

${ }^{a}$ Note: $x$ and $y$ denote the surface area obtained from Landsat and MODIS, respectively.

\subsection{Changes of lake area and level}

Figure 3 shows the changes of both surface area and water level of the five selected lakes. There was good agreement between variations of water level and surface area, which means that rising/falling lake level is correspondent to expanding/shrinking lake area. It can be seen that at PYC, TRC and ZNC there were overall upward trends in water level and surface area of the lake system during the past decades. On the contrary, water level and surface area of MYC and PYC exhibited a consistent downward trend.

During the period 2000-2012, water levels of PYC, TRC and ZNC were almost always above the long-term average, whereas those of MYC and PYC were below the long-term average. As presented in Table 5, compared with that before the year 2000, mean water levels of PYC, TRC and ZNC in the period 2000-2012 were $0.66 \mathrm{~m}, 0.62 \mathrm{~m}$ and $0.12 \mathrm{~m}$ higher, accompanying the expansion in surface area by $5.1 \mathrm{~km}^{2}, 3.14 \mathrm{~km}^{2}$ and $16.28 \mathrm{~km}^{2}$, respectively. For lakes MYC and PKC, however, water level fell at a rate of $0.09 \mathrm{~m}$ and $1.10 \mathrm{~m}$, respectively, and the area of the lakes shrunk by $3.05 \mathrm{~km}^{2}$ and $6.08 \mathrm{~km}^{2}$, respectively. 

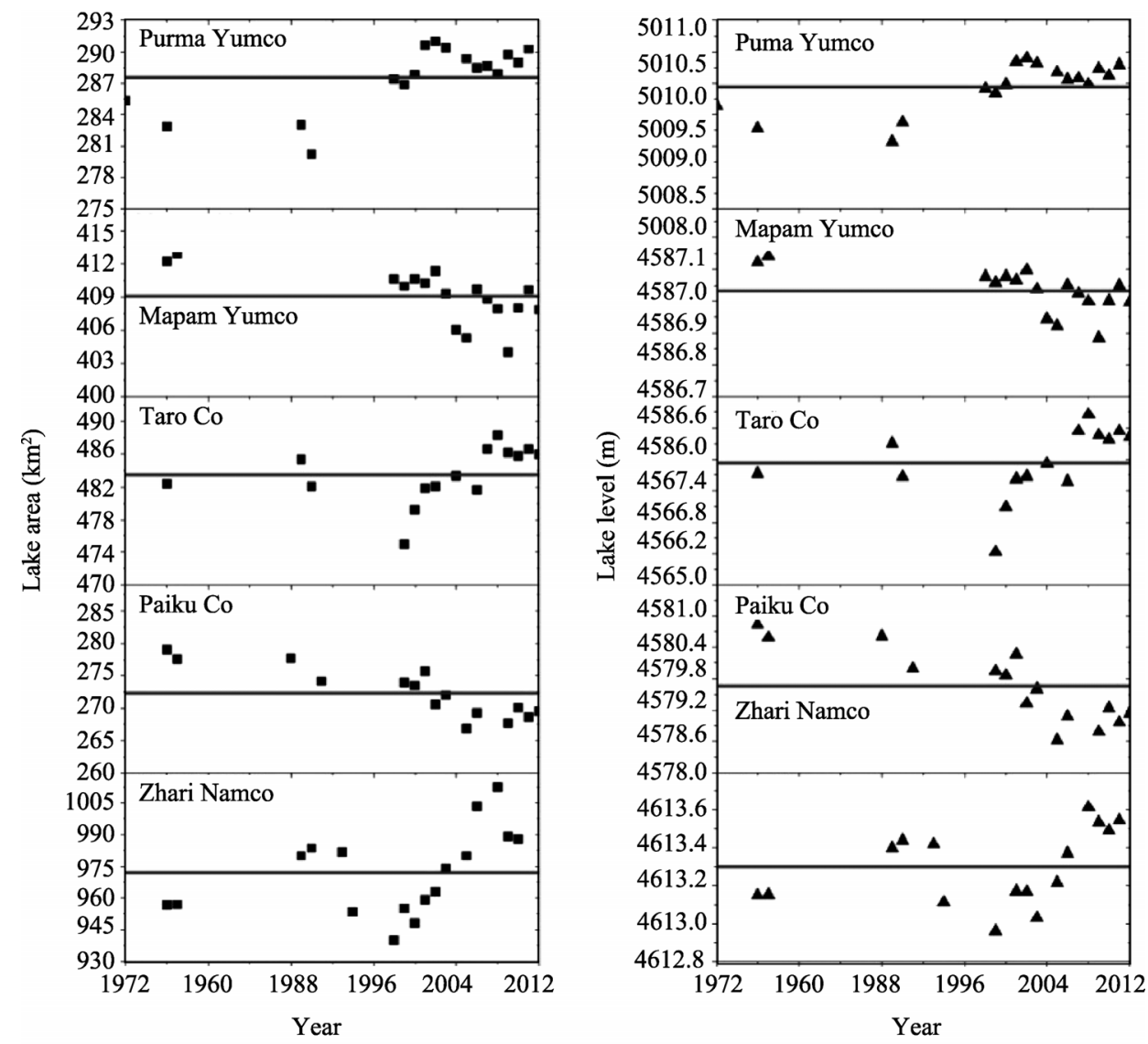

Figure 3 Changes of area and level for lakes in the Tibetan Plateau during the past decades

Table 5 Changes of lake area $\left(\mathrm{km}^{2}\right)$ and lake level $(\mathrm{m})$ of the five lakes

\begin{tabular}{|c|c|c|c|c|c|c|}
\hline \multirow{2}{*}{ Lake } & \multicolumn{2}{|c|}{ 1972-1999 } & \multicolumn{2}{|c|}{ 2000-2012 } & \multicolumn{2}{|c|}{ Change } \\
\hline & Area & Lake level & Area & Lake level & Area & Lake level \\
\hline PYC & 284.25 & 5009.52 & 289.35 & 5010.18 & 5.10 & 0.66 \\
\hline TRC & 481.15 & 4566.88 & 484.29 & 4567.50 & 3.14 & 0.62 \\
\hline ZNC & 963.26 & 4613.23 & 979.54 & 4613.35 & 16.28 & 0.12 \\
\hline MYC & 411.42 & 4587.00 & 408.37 & 4586.91 & -3.05 & -0.09 \\
\hline PKC & 276.41 & 4580.39 & 270.33 & 4579.29 & -6.08 & -1.10 \\
\hline
\end{tabular}

\subsection{Spatial coherence of changes in the lake systems}

As presented in Figure 3, there was no general agreement in the variation of surface area and water level among the five lakes selected in this study, which could be attributed to differences in lake system characteristics and the corresponding driving forces. The correlation of water level between any two lakes shows the spatial coherence of a lake system (Table 6).

It was found that there was a significant positive correlation between ZNC and TRC in terms of water level change over the past decades, where the correlation coefficient reached 0.83. It is worth noting that the two lakes (ZNC and TRC) experiencing water level increases are located in the southern Qiangtang alpine grasslands, which belongs to the semi-arid 
Table 6 Lake level correlation matrix of the selected lakes

\begin{tabular}{cccccc}
\hline Lake & PYC & TRC & ZNC & MYC & PKC \\
\hline PYC & 1.0 & & & & \\
TRC & 0.11 & 1.0 & & & \\
ZNC & -0.11 & $0.83^{*}$ & 1.0 & 1.0 & 1.0 \\
MYC & -0.33 & -0.38 & -0.26 & $0.75^{*}$ & -0.22 \\
PKC & $-0.68^{*}$ & -0.37 & & & \\
\hline
\end{tabular}

*Correlation coefficient is significant at the level of 0.01 .

climate zone. A significant positive correlation of lake level variation was detected between MYC and PKC, located at the fringe of the Tibetan Plateau, with a correlation coefficient of 0.75 , suggesting that the coherence of water level change may be the result of similar environmental drivers. In contrast to the observations at ZNC and TRC, MYC and PKC were seen to be shrinking, with lowering water levels. Fluctuations in the level of PYC were inconsistent with those of the other four lake systems, and the water levels of PYC showed a significant negative correlation with those of PKC. The different changes among the lake systems may indicate the diverse impacts of climate change.

\subsection{Climate change impacts on lake systems}

Changes in water level and surface area of the lakes could be the consequence of regional climate change. Figure 4 shows the variations in precipitation and temperature for the five lakes over the past decades, which is based on the observation records from the nearest meteorological stations (He et al., 2011; Chen et al., 2007). It can be seen that there was no significant trend in the long-term change in precipitation at all five lakes. Compared with the period before 2000, however, the mean annual precipitation for the period 2000-2012 at TRC and ZNC was $37 \mathrm{~mm}$ higher, which could have resulted in the expansion and rising of the lake systems. In contrast, mean annual precipitation at MYC and PKC for the period 2000-2012 was $9.6 \mathrm{~mm}$ and $60.7 \mathrm{~mm}$ lower, respectively, than that of the period before 2000, leading to shrinking and falling water levels of the lake systems. For the same period, no significant change of mean annual precipitation was found in PYC.

As shown in Figure 4, there was general agreement regarding a warming climate at all five lakes. The rates of temperature increase at PYC, TRC, ZNC, MYC and PKC were $0.28{ }^{\circ} \mathrm{C} / 10$ years, $0.51{ }^{\circ} \mathrm{C} / 10$ years, $0.51{ }^{\circ} \mathrm{C} / 10$ years, $0.43{ }^{\circ} \mathrm{C} / 10$ years, and $0.27{ }^{\circ} \mathrm{C} / 10$ years, respectively. The higher temperature, on the one hand, could result in less runoff into the lakes and higher evaporation loss from the lakes. Yang et al. (2011) reported that evaporation in the central region of the Tibetan Plateau increased steadily between 1980 and 2000, which resulted in a slight decrease in runoff. As a consequence, lake water storage could be reduced and would be reflected by a decreasing water level and shrinking surface area. As in the cases of $\mathrm{ZNC}$ and TRC, on the other hand, a warmer climate may accelerate glacier retreatment (Shangguan et al., 2008; Yao et al., 2007; Li et al., 2007) accompanied by more glacier-melt flow into the lake system to increase the water level (Xie et al., 2010; Kang et al., 2007; Liu et al., 2000; Wu et al., 2005).

It is worth pointing out that the changes in water level and surface area are reflections of water storage changes in the lake system, which depend on the balance between water 

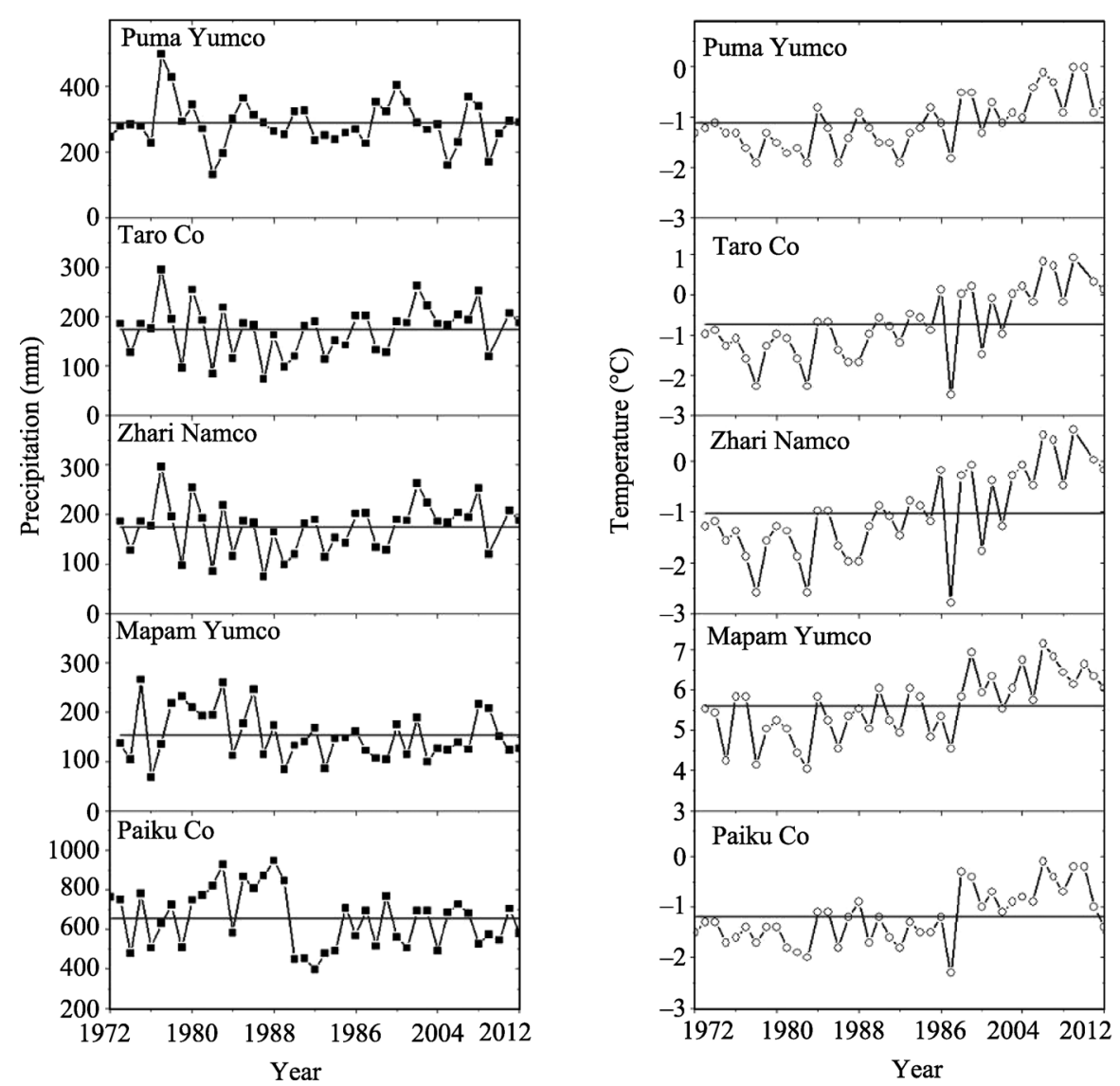

Figure 4 Changes in annual precipitation and temperature of the five lakes during 1972-2012

gained and water loss. For lakes (e.g., PKC and MYC) in the fringe area along the southern Tibetan Plateau, the water gained mainly relies on precipitation (Dai et al., 2013). Hence, a significant decrease in precipitation could be the dominant driver of falling water levels in the lake systems.

\section{Conclusions}

The lake system in the Tibetan Plateau has shown sensitive responses to global warming as indicated by changes in parameters such as water level and surface area. In this study, to investigate long-term changes in the lake system under the impacts of climate change, a multi-source RS dataset was used to retrieve water level and surface area data for the period 1972-2012. Five lakes in the south-central Tibetan Plateau were selected for the study, including Puma Yumco (PYC), Taro Co (TRC), Zhari Namco (ZNC), Mapam Yumco (MYC), and Paiku Co (PKC).

The results showed an increase in water level of PYC, TRC, and ZNC accompanied by significant expansion of lake surface areas for the period 1972-2012. Meanwhile, the water levels of PKC and MYC dropped, accompanied by a shrinking surface area. The different changes in the lake systems suggest the diversified impacts of climate change in the Tibetan Plateau. Spatially, lakes in the central plateau (e.g., ZNC and TRC) showed a consistent up- 
ward trend in water level, while lakes at the southern fringe of the plateau (e.g., PKC and MYC) showed similar downward trends. The results also suggested that the water balance of the lake system in the Tibetan Plateau has been experiencing greater changes in the most recent decade. To further explore the impacts of climate change on the lake system, investigation of the dynamics of lake water balance is an urgent priority.

\section{Acknowledgements}

We thank the Climate Data Center, National Meteorological Information Center, China Meteorological Administration, for providing the long-time meteorological data of the four field stations. This research was jointly supported by The "Strategic Priority Research Program (B)" of the Chinese Academy of Sciences (Grant XDB03030406), and the National Natural Science Foundation of China (Grant 41371218, 41165011).

\section{References}

Chander G, Markhamb B L, Helder D L, 2009. Summary of current radiometric calibration coefficients for Landsat MSS, TM, ETM+, and EO-1 ALI sensors. Remote Sensing of Environment, 113 (5): 893-90.

Chen X, Cui P, Li Y et al., 2007. Changes in glacial lakes and glaciers of post-1986 in the Poiqu River basin, Nyalam, Xizang (Tibet). Geomorphology, 88(3): 298-311.

Dai Y, Gao Y, Zhang G et al., 2013. Water volume change of the Peiku Co in the southern Tibetan Plateau and its response to climate change in 2003-2011. Journal of Glaciology and Geocryology, 35(3): 723-732. (in Chinese)

Ding F, 2009. A new method for fast information extraction of water bodies using remotely sensed data. Remote Sensing Technology and Application, 24(2): 167-171. (in Chinese)

He J, Yang K, 2011. China Meteorological Forcing Dataset. Cold and Arid Regions Science Data Center at Lanzhou. http://westdc.westgis.ac.cn/. (in Chinese)

Kang S, Chen F, Ye Q et al., 2007. Glacier retreating dramatically on the Mt. Nyainqentanglha during the last 40 years. Journal of Glaciology and Geocryology, 29(6): 869-873. (in Chinese)

Kropáčk J, Maussion F, Chen F, 2013. Analysis of ice phenology of lakes on the Tibetan Plateau from MODIS data. The Cryosphere, 7(1): 287-301.

Lei Y, Yao T, Bird B W et al., 2013. Coherent lake growth on the central Tibetan Plateau since the 1970s: Characterization and attribution. Journal of Hydrology, 483: 61-67.

Li J, Sheng Y, Luo J, 2011. Automatic extraction of Himalayan glacial lakes with remote sensing. Journal of Remote Sensing, 15(1): 29-43. (in Chinese)

Li X, Xu H, Sun Y et al., 2007. Lake-level change and water balance analysis at Lake Qinghai, west China during recent decades. Water Resources Management, 21(9): 1505-1516.

Liu J, Wang S, Yu S et al., 2009. Climate warming and growth of high-elevation inland lakes on the Tibetan Plateau. Global and Planetary Change, 67(3): 209-217.

Liu X, Chen B, 2000. Climatic warming in the Tibetan Plateau during recent decades. International Journal of Climatology, 20(14): 1729-1742.

Lu C, Yu G, Xie G, 2005. Tibetan Plateau serves as a water tower. Geoscience and Remote Sensing Symposium, 2005, IGARSS'05. Proceedings. IEEE International. 3120-3123.

Markham B L, Helder D L, 2012. Forty-year calibrated record of earth-reflected radiance from Landsat: A review. Remote Sensing of Environment, 122: 30-40.

McFeeters S K, 1996. The use of the Normalized Difference Water Index (NDWI) in the delineation of open water features. International Journal of Remote Sensing, 17(7): 1425-1432.

Meng K, Shi X, Wang E et al., 2012. High-altitude salt lake elevation changes and glacial ablation in Central Tibet, 2000-2010. Chinese Science Bulletin, 57(7): 571-579. (in Chinese) 
Qiu J, 2008. China: The Third Pole. Nature News, 454(7203): 393-396.

Shangguan D, Liu S, Ding Y et al., 2008. Thinning and retreat of Xiao Dongkemadi glacier, Tibetan Plateau, since 1993. Journal of Glaciology, 54: 949-951.

Solomon S, Qin D, Manning M et al. (editors), 2007. Contribution of Working Group I to the Fourth Assessment Report of the Intergovernmental Panel on Climate Change, 2007: The Physical Science Basis: Summary for Policymakers. Cambridge, UK: Cambridge University Press.

Wu S, Yin Y, Zheng D et al., 2005. Climate changes in the Tibetan Plateau during the last three decades. Acta Geographica Sinica, 60(1): 3-11. (in Chinese)

$\mathrm{Wu}$ Y, Zhu L, 2008. The response of lake-glacier variations to climate change in Nam Co Catchment, central Tibetan Plateau, during 1970-2000. Journal of Geographical Sciences, 18(2): 177-189.

Xie H, Ye J, Liu X et al., 2010. Warming and drying trends on the Tibetan Plateau (1971-2005). Theoretical and Applied Climatology, 101(3/4): 241-253.

$\mathrm{Xu} \mathrm{H}, 2005$. A study on information extraction of water body with the Modified Normalized Difference Water Index (MNDWI). Journal of Remote Sensing, 9(5): 589-595. (in Chinese)

Yan P, Zhang Y, Zhang Y, 2007. A study on information extraction of water system in semi-arid regions with the Enhanced Water Index (EWI) and GIS based noise remove techniques. Remote Sensing Information, 62-67. (in Chinese)

Yang K, Ye B, Zhou D et al., 2011. Response of hydrological cycle to recent climate changes in the Tibetan Plateau. Climatic Change, 109(3/4): 517-534.

Yao T, Pu J, Lu A et al., 2007. Recent glacial retreat and its impact on hydrological processes on the Tibetan Plateau, China, and surrounding regions. Arctic, Antarctic, and Alpine Research, 39(4): 642-650.

Yao T, Zhu L, 2006. The response of environmental changes on Tibetan Plateau to global changes an adaptation strategy. Advances in Earth Science, 21(5): 459-464.

Ye Q, Zhu L, Zheng H et al., 2007. Glacier and lake variations in the Yamzhog Yumco basin, southern Tibetan Plateau, from 1980 to 2000 using remote-sensing and GIS technologies. Journal of Glaciology, 53(183): 673-676.

Zhang B, Wu Y, Zhu L et al., 2011a. Estimation and trend detection of water storage at Nam Co Lake, central Tibetan Plateau. Journal of Hydrology, 405(1): 161-170.

Zhang G, Xie H, Duan S et al., 2011b. Water level variation of Lake Qinghai from satellite and in situ measurements under climate change. Journal of Applied Remote Sensing, 5(1): 053532-053532-15.

Zhang G, Xie H, Kang S et al., 2011c. Monitoring lake level changes on the Tibetan Plateau using ICESat altimetry data (2003-2009). Remote Sensing of Environment, 115(7): 1733-1742.

Zhang G, Xie H, Yao T et al., 2013. Water balance estimates of ten greatest lakes in China using ICESat and Landsat data. Chinese Science Bulletin, 58(26): 2664-2678.

Zhu L, Xie M, Wu Y, 2010. Quantitative analysis of lake area variations and the influence factors from 1971 to 2004 in the Nam Co basin of the Tibetan Plateau. Chinese Science Bulletin, 55(13): 1294-1303. 